\title{
Domination of gastric Complications Among Diabetic Patients
}

\author{
Abdul Kader Mohiuddin* \\ Department of Pharmacy, Bangladesh \\ *Corresponding author: Abdul Kader Mohiuddin, Department of Pharmacy, 151/8, Green Road, Dhanmondi, Dhaka - 1205, \\ Bangladesh
}

\begin{tabular}{|c|c|}
\hline ARTICLE INFO & ABSTRACT \\
\hline Received: 蔧 July 09, 2019 & Citation: Abdul Kader Mohiuddin. Domination of gastric Complications Among Diabetic \\
\hline & Patients. Biomed J Sci \& Tech Res 19(4)-2019. BJSTR. MS.ID.003331. \\
\hline
\end{tabular}

\section{Editorial}

Up to $50 \%$ of patients with type 1 and 2 diabetes mellitus (DM) and suboptimal glycemic control have delayed gastric emptying (GE), which can be documented with scintigraphy, 13 C-breath tests, or a wireless motility capsule; the remainder have normal or rapid GE [1-3]. Also, it has been determined that $29 \%$ of patients with gastroparesis had diabetes mellitus [4], 13\% developed symptoms after gastric surgery and $36 \%$ were idiopathic. About $12 \%$ of global health care expenditure (727 billion USD) is spent on diabetes. When expanded to the age group between 18 and 99 years, the cost would total to 850 billion USD. In conjunction with the rising prevalence, the cost is expected to rise to a staggering 958 billion USD by 2045. In the USA, an estimated 5 million patients suffer from some form of gastroparesis, and the female: male ratio is $4: 1$. Many patients with delayed GE are asymptomatic; others have dyspepsia (i.e., mild-moderate indigestion, with or without a mild delay in GE) or gastroparesis (GP), which is a syndrome characterized by moderate-severe upper gastrointestinal symptoms and delayed GE that suggest, but are not accompanied by, gastric outlet obstruction [5]. GP can markedly impair quality of life and up to $50 \%$ of patients have significant anxiety and/or depression [1], [6-8].

In diabetic patients (without neuropathy) and healthy controls, acute hyperglycemia will instead relax the proximal stomach, and suppress gastric electrical activity (e.g., reduced the frequency, propagation, and contraction of the antrum) in both fasting and post-prandial conditions, thereby slowing gastric emptying [9]. Abdominal pain is often epigastric (43\%), postprandial (72\%), nocturnal (74\%), and frequently associated with interference with sleep (66\%) [7]. Early satiety (88\%), and bloating (64\%) were the most common symptoms, however $94 \%$ of patients had resolution of their symptoms a year after their operation [10]. Severe/very severe upper abdominal pain occurred in 34\% of GP patients and associated with other gastroparesis symptoms, somatization, and opiate medication use [11]. Nausea and vomiting are more common in diabetic gastroparesis (DGP) whereas abdominal pain and early satiety are more frequent in idiopathic gastroparesis.

The 3 main causes of gastroparesis are diabetic, postsurgical, and idiopathic [12]. In diabetes, measuring gastric emptying has an additional justification in determining the absorption of orally administered drugs and nutrients, and thus post-prandial glucose regulation. Indeed, new onset or worsening of existing difficulties in blood glucose regulation may be the first symptom of diabetic gastroparesis [2]. Growing clinical evidence shows that delayed GE (in GP patients) may be a factor associated with severe reflux, dyspepsia, or both. Gastroparesis, concomitant in $25 \%$ of patients with gastroesophageal reflux disease (GERD), has been shown to improve after Nissen fundoplication [13]. If a doctor suspects a person with diabetes has gastroparesis, he will typically order one or more of the following tests to confirm the diagnosis: Barium X-ray; Barium beefsteak test; Radioisotope gastric-emptying scan; Gastric manometry Blood tests to check for nutritional deficiencies and electrolyte imbalances that are common with gastroparesis; Imaging of the gallbladder, kidneys, and pancreas to rule out gallbladder problems, kidney disease, or pancreatitis as causes; An upper endoscopy to check for abnormalities in the structure of the stomach [14].

It is critical to clearly distinguish patients with functional dyspepsia (FD) from those with GP and to better understand the relationship among alterations in specific symptoms, GE, and altered peripheral and central sensory responses to gastric stimuli [15]. A similar situation may occur in a misguided attempt 
to improve gastric health by using the ubiquitously prescribed proton pump inhibitors, $\mathrm{H} 2$ receptor antagonists, and sucralfate or aluminum hydroxide-based antacids. These drugs are a cause of delayed gastric emptying. Such "therapeutic adventures", akin to a pyromaniac leading a firefighting operation, may harm rather than improve diabetic gastroparesis. A combination of acid-suppressing and prokinetic drugs is indicated only if dyspepsia and gastroparesis co-exist with each other [16]. Vagal dysfunction has also been postulated to play a role in DGP. When food is ingested and gastric accommodation is impaired, patients may experience symptoms such as early satiation, fullness and discomfort. Animal and human data suggest that vagal neuropathy can lead to reduction in pyloric relaxation, impaired antral contraction and disturbed antro-pyloric coordination [17].

GP has also been associated with bronchiectasis, aspiration and chronic rejection. GI bleeding secondary to severe refractory esophagitis with an eventual necessity for surgery has also been reported [18]. Most patients respond to conservative treatment with frequent small meals and an upright eating position, in combination with motility agents, such as oral erythromycin analogs, metoclopramide, and domperidone (the last of these is not FDA approved in the US) [19]. Metoclopramide and domperidone, a D2 dopamine receptor antagonist, are the most widely used but only metoclopramide is FDA approved in the US while domperidone is available in Europe, Canada, Mexico, and New Zealand. Metoclopramide also carries a significant risk of extrapyramidal adverse effects, including tardive dyskinesia when taken longer than 12 wk. Other groups of medication, such as 5-HT3 receptor antagonists, phenothiazines, and muscarinic cholinergic receptor antagonist, have been used off-label for symptomatic relieve but they do not have effect of gastric motility. While medications and dietary modification are the first line treatment, approximately $30 \%$ of patients do not respond to conservative management.

These limitations of medical therapy highlight the need for an alternate therapeutic option [20]. Traditional therapy for delayed gastric emptying has focused on supportive treatment, and there is no significant effective therapy. Low-energy shock wave can increase gastric contraction and emptying by activating axonal regeneration and increasing myenteric plexus, but not related with motility peptides [3,21]. Gastric electrical stimulation (GES) (Enterra, Medtronics, Inc.) was approved by FDA in 2000 as a Humanitarian Use Device for patients with refractory diabetic or idiopathic gastroparesis. On the other hand, high-frequency stimulation (HFS) has no effect on gastric emptying but is able to significantly reduce symptoms of nausea and vomiting in gastroparetic patients. [22]. Compared to the use of single point electrodes, the use of two low-resolution electrodes allows recording gastric electrical wave propagation with greater detail. Low resolution recording appears to be superior to single point recordings, while awaiting practical high-resolution recordings [23].
Abell et al. concluded that electrical stimulation improves symptoms and physiology with (a) an early and sustained antiemetic effect; (b) an early and durable gastric prokinetic effect in delayed emptying patients; (c) an early anti-arrhythmic effect that continues over time; (d) a late autonomic effect; (e) a late hormonal effect; (f) an early anti-inflammatory effect that persists; and (g) an early and sustained improvement in health-related quality of life [24]. GES improved symptoms in $75 \%$ of patients with $43 \%$ being at least moderately improved. Nausea, loss of appetite, and early satiety responded the best [25]. Advances to better understand the pathophysiology and management of diabetic gastroparesis have been limited, especially with discordance between symptoms and severity of delay in gastric emptying. Established treatment options are limited; however, recent pharmacologic and surgical interventions show promise [26].

\section{References}

1. Bharucha AE, Kudva YC, Prichard DO (2019) Diabetic Gastroparesis. Endocr Rev.

2. Sangnes DA, Søfteland E, Teigland T, Dimcevski G (2019) Comparing radiopaque markers and (13)C-labelled breath test in diabetic gastroparesis diagnostics. Clin Exp Gastroenterol 12: 193-201.

3. Wu KL, Chiu YC, Yao CC, Tsai CE, Hu ML, et al. (2019) Effect of extracorporeal low-energy shock wave on diabetic gastroparesis in a rat model. J Gastroenterol Hepatol 34(4): 720-727.

4. Alipour Z, Khatib F, Tabib SM, Javadi H, Jafari E, et al. (2017) Assessment of the Prevalence of Diabetic Gastroparesis and Validation of Gastric Emptying Scintigraphy for Diagnosis. Mol Imaging Radionucl Ther 26(1): 17-23.

5. Krishnasamy S, Abell TL (2018) Diabetic Gastroparesis: Principles and Current Trends in Management. Diabetes Ther 9(1): 1-42.

6. WoodhouseS, Hebbard G, Knowles SR (2017) Psychological controversies in gastroparesis: A systematic review. World J Gastroenterol 23(7): 1298-1309.

7. Avalos DJ, Sarosiek I, Loganathan P, Mc Callum RW (2018) Diabetic gastroparesis: current challenges and future prospects. Clin Exp Gastroenterol 11: 347-363.

8. Teigland T, Iversen MM, Sangnes DA, Dimcevski G, Søfteland E, et al. (2018) A longitudinal study on patients with diabetes and symptoms of gastroparesis - associations with impaired quality of life and increased depressive and anxiety symptoms. J Diabetes Complications 32(1): 8994.

9. Aswath GS, Foris LA, Patel K (2019) Diabetic Gastroparesis In Stat Pearls. Treasure Island (FL): Stat Pearls Publishing.

10. Liu N, Abell T (2017) Gastroparesis Updates on Pathogenesis and Management. Gut Liver 11(5): 579-589.

11. Parkman HP, Wilson LA, Hasler WL, Mc Callum RW, Sarosiek I (2019) Abdominal Pain in Patients with Gastroparesis: Associations with Gastroparesis Symptoms, Etiology of Gastroparesis, Gastric Emptying, Somatization, and Quality of Life. Dig Dis Sci 1-14.

12. Shen S, Xu J, Lamm V, Vachaparambil CT, Chen H, et al. (2019) Diabetic Gastroparesis and Nondiabetic Gastroparesis. Gastrointest Endosc Clin N Am 29(1): 15-25.

13. Noar MD, Noar E (2008) Gastroparesis associated with gastroesophageal reflux disease and corresponding reflux symptoms may be corrected by radiofrequency ablation of the cardia and esophagogastric junction. Surg Endosc 22(11): 2440-2444. 
14. Fletcher J (2019) What to know about diabetic gastroparesis? Reviewed by Saurabh (Seth) Sethi, MD MPH. Medical News Today.

15. Kim BJ, Kuo B (2019) Gastroparesis and Functional Dyspepsia: A Blurring Distinction of Pathophysiology and Treatment. J Neurogastroenterol Motil 25(1): 27-35

16. Kalra S, Sharma A, Priya G (2018) Diabetic Gastroparesis. Diabetes Ther 9(5): 1723-1728.

17. Christophe Vanormelingen, Jan Tack, Christopher N Andrews (2013) Diabetic gastroparesis. British Medical Bulletin 105(1): 213-230

18. Naik Mathuria B, Jamous F, Noon GP, Loebe M, Seethamraju H, et al. (2006) Severe gastroparesis causing splenic rupture: a unique, early complication after heart-lung transplantation. Tex Heart Inst J 33(4): 508-511.

19. Akindipe OA, Faul JL, Vierra MA, Triadafilopoulos G, Theodore J, et al. (2000) The surgical management of severe gastroparesis in heart/lung transplant recipients. Chest 117(3): 907-910.

20. Mekaroonkamol P, Shah R, Cai Q (2019) Outcomes of per oral endoscopic pyloromyotomy in gastroparesis worldwide. World J Gastroenterol 25(8): 909-922.

ISSN: 2574-1241

DOI: 10.26717/BJSTR.2019.19.003331

Abdul Kader Mohiuddin. Biomed J Sci \& Tech Res

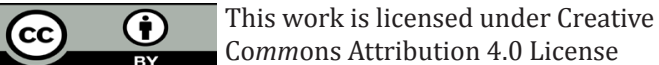

Submission Link: https://biomedres.us/submit-manuscript.php
21. Atassi H, Abell TL (2019) Gastric Electrical Stimulator for Treatment of Gastroparesis. Gastrointest Endosc Clin N Am 29(1): 71-83.

22. Lin Z, Forster J, Sarosiek I, Mc Callum RW (2003) Treatment of gastroparesis with electrical stimulation. Dig Dis Sci 48(5): 837-848.

23. Hasanin M, Amin O, Hassan H, Kedar A, Griswold M, et al. (2019) Temporary Gastric Stimulation in Patients With Gastroparesis Symptoms: Low-Resolution Mapping Multiple Versus Single Mucosal Lead Electrograms. Gastroenterology Res 12(2): 60-66.

24. Abell TL, Kedar A, Stocker A, Beatty K, Mc Elmurray L, et al. (2019) Gastroparesis syndromes: Response to electrical stimulation. Neurogastroenterol Motil 31(3): e13534.

25. Heckert J, Sankineni A, Hughes WB, Harbison S, Parkman H, et al. (2016) Gastric Electric Stimulation for Refractory Gastroparesis: A Prospective Analysis of 151 Patients at a Single Center. Dig Dis Sci 61(1): 168-175.

26. Kumar M, Chapman A, Javed S, Alam U, Malik RA, et al. (2018) The Investigation and Treatment of Diabetic Gastroparesis. Clin Ther 40(6): 850-861.

$\begin{array}{ll}\text { BIOMEDICAL } & \text { Assets of Publishing with us } \\ \text { RESEARCHES } & \text { - Global archiving of articles } \\ & \text { - Immediate, unrestricted online access } \\ & \text { - Rigorous Peer Review Process } \\ \end{array}$

